\title{
Polikistik Over Sendromu ve Obezite: FTO ve MC4R Gen
}

\section{Polimorfizmlerinin Rolü}

\author{
Polycystic Ovary Syndrome and Obesity: The Role of FTO and MC4R Gene \\ Polymorphisms
}

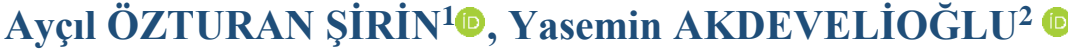 \\ ${ }^{1}$ Adnan Menderes Üniversitesi Sağlık Bilimleri Fakültesi Beslenme ve Diyetetik Bölümü \\ ${ }^{2}$ Gazi Üniversitesi Sağlık Bilimleri Fakültesi Beslenme ve Diyetetik Bölümü
}

ÖZ

\begin{abstract}
Polikistik Over Sendromu (PKOS) etiyolojisi karmaşık olan multifaktöriyel bir endokrin bozukluktur. Ayrıca kadınlarda obezite ve tip 2 diyabet gelişim riskini arttıran metabolik bozukluklarla da ilişkilidir. Obezite/adipozite ve insülin direnci PKOS'lu kadınlarda oldukça sık karşılaşılan bir problemdir. İnsan genomunun ayrıntılı olarak incelendiği genom projelerinde obezite ve bazı hastalıklarla ilişkili çok sayıda gen ve genetik varyasyonların bulunduğu gösterilmiştir. Bu genler içerisinde yağ kütlesi ve obezite ile ilişkili gen (FTO) ve melanokortin-4 reseptör geni (MC4R) varyantları obezite, aşırı vücut ağırlığı ve tip 2 diyabet ile ilişkilidir. Bu nedenle FTO ve MC4R genlerinin obezite/adipozite gelişimine etkileri yoluyla PKOS ile ilişkili olabileceği öne sürülmektedir. Bu derleme makalede obeziteyle ilişkili bazı gen polimorfizmlerinin (FTO ve MC4R) PKOS ile ilişkisi incelenmiştir.
\end{abstract}

Anahtar Kelimeler: Obezite, PKOS, FTO, MC4R.

ABSTRACT

Polycystic Ovary Syndrome (PCOS) is a multifactorial endocrine disorder with a complex etiology. It is also associated with metabolic disorders that increase the risk of developing obesity and type 2 diabetes in women. Obesity / adiposity and insulin resistance is a common problem in women with PCOS. Genome projects, which examine the human genome in detail, have been shown to have a large number of genes and genetic variations associated with obesity and some diseases. Among these genes, fat mass and obesity-associated gene (FTO) and melanocortin-4 receptor gene (MC4R) variants are associated with obesity, excess body weight, and type 2 diabetes. Therefore, it is suggested that genes, FTO and MC4R, may be associated with PCOS through the effects of obesity / adiposity development. In this review article, the relationship of some obesityrelated gene polymorphisms (FTO and MC4R) with PCOS has been investigated.

Key words: Obesity, PCOS, FTO, MC4R.

\section{GíRiş}

Polikistik over sendromu (PKOS), günümüzde reprodüktif çağdaki kadınlarda sıklıkla görülen metabolik ve endokrinolojik bir hastalıktır. Prevelansı tanıda hangi kriterlerin kullanıldığına göre değişmektedir. Ancak sıklıkla Avrupa İnsan Üreme ve Embriyoloji Derneği / Amerikan Üreme Tıbbı Derneği'nin belirlemiş olduğu Rotterdam Kriterleri kullanılmakta ve buna göre kadınlarda PKOS görülme sıklığı \%15-20 olarak bildirilmektedir (1).

Yapılan çalışmalarda, PKOS'un kalıtsal olduğu bildirilmekte ve spesifik bir genetik nedeni tanımlamaya yönelik çeşitli yaklaşımlar ileri sürülmektedir (2-4). Sendromun 
patogenezine yönelik var olan bilgiler, PKOS'un karmaşık bir multigenik bozukluk olduğunu da düşündürmektedir (5). PKOS için genetik yatkınlık değerlendirilmiş, PKOS'lu hastaların birinci derece yakınlarda yüksek androjen seviyeleri, artmış insülin direnci prevelansı ve kardiyovasküler hastalıkların görülme sıklığının yüksek olduğu bulunmuştur (6-8). Polikistik over sendromlu bireylerin annelerinin \%35'inin, kız kardeşlerin de \%40'1nın sendromun özelliklerini taşıdığı bildirilmiştir (3). Bu sendromun belirlenmiş bir erkek fenotipi bulunmamakla birlikte PKOS'lu kadınların erkek akrabalarında obezite ve insülin direnci görülme sıklıkları yüksek bulunmuştur $(9,10)$.

Genel olarak, PKOS'ta obezite görülmesi üreme fonksiyonlarını ve endokrin durumu önemli ölçüde değiştirir. Polikistik over sendromu ile obezitenin birlikte görülmesi kötü androjenik profil ile ilişkili olup menstrüel düzensizlik oranını ve endometriyal kanser riskini arttırır. Sendrom patogenezinde metabolik değişiklikler, hiperandrojenizm, yumurtlama ve doğurganlık üzerine etkilerinden dolayı obezitenin önemi vurgulanmaktadır. Ayrıca PKOS'ta vücut ağırlığı kaybının sağladığı olumlu etkilerden de bahsedilmektedir. Bu durumun koruyucu hekimlikte büyük önem taşıyabileceği ve PKOS'un gelişimini destekleyen genetik ve çevresel geçmiş hakkındaki sınırlı bilginin genişletilmesine fırsat sağlayabileceği ifade edilmektedir (11).

\section{Obeziteyle ilişkili gen polimorfizmleri}

Genlerde meydana gelen polimorfizmlerin çeşitli hastalıklar ile ilişkili olduğu bildirilmektedir. Polimorfizm, bahsedilen genin Deoksiribo Nükleik Asit (DNA) dizisinde gen fonksiyonunda bir değişime neden olmadan oluşan değişiklik olarak bildirilmektedir (12). Mutasyon ise gen ya da kromozomda meydana gelen kalıcı ve yapısal değişikliklerdir (13). Tek nükleotid polimorfizmleri (SNP) ise DNA dizisindeki adenin (A), guanin (G), sitozin (S), timin (T) baz çiftinden birinin diğer baz çifti ile değişmesidir. Oluşan SNP'ler çoğunlukla protein yapısında ve fonksiyonunda değişikliğe neden olmamaktadır (14). Baz çiftlerinde oluşan değişiklikler ile bazı insanların kromozomlarının belirli bölgelerinde $\mathrm{A}$, bazılarında $\mathrm{T}$ bazı bulunabilir. Bu formlardan herhangi biri de "allel" olarak adlandırılmaktadır (15). Obezite ile ilişkili olarak gösterilen en önemli SNP'lerden ikisi FTO (yağ kütlesi ve obezite ile ilişkili gen) ve MC4R (melanokortin-4 reseptör geni) genlerinin belirli bölgelerinde meydana gelen SNP'lerdir $(16,17)$.

\section{Yă̆ kütlesi ve obeziteyle ilişkili gen}

Transgenik farelerin obezite fenotipleri ve Genom çapında ilişkilendirme çalışmaları (GWAS) obeziteyle ilgili yeni genlerin keşiflerini beraberinde getirmiştir. Bulunan yeni gen keşifleri içerisinde farklı popülasyonlarda obezite ve yağ kütlesi ile ilişkili olduğu saptanan ilk ve en güçlü genin FTO proteini kodlayan gen olduğu öne sürülmektedir (16). Homo sapiens FTO geni 16. kromozomda 16q12.2 pozisyonunda yer almaktadır $(18,19)$. İnsanda birçok organda ekspresyonu gerçekleşmekle birlikte FTO geni, iştah davranışı ve yă̆ asidi metabolizmasından sorumlu olan beynin hipotalamus, beyincik ve hipokampus bölgelerinde daha yoğun bulunmaktadır $(20,21)$. FTO geninin kesin olmamakla birlikte eksprese olduğu dokular nedeniyle enerji alımının hipotalamik kontrolünde, enerji harcamasında, adipogenezde ve iskelet kaslarının mitokondriyal fonksiyonunda fizyolojik rolü olduğu öne sürülmektedir (22). Ayrıca FTO proteininin nükleik asitlerin demetilasyonunda da rol oynadığı 
bildirilmektedir. $\mathrm{Bu}$ nedenle transkripsiyonel koaktivatör olarak işlev gösterdiği belirtilmektedir (23). Bu gen aynı zamanda $\mathrm{Fe}+2$ ve 2 -okzoglutarata ( $\alpha$-ketoglutarat) bağımlı nükleik asit dimetilazı kodlamaktadır (24).

Yapılan çalışmalarda FTO’yla ilgili farklı SNP'lerle (rs1861868, rs1421085, rs805136, rs17817449, rs1121980) obezite arasında ilişki görülmekle birlikte özellikle FTO geninin ilk nitronunda meydana gelen SNP'lerin (rs9939609) ve mutasyonların obezite ve yağ kütlesi artış1 ile ilişkili olduğu gösterilmiştir (25-27). Literatürde FTO geni rs9939609 SNP'sinde "A alleli" obezite açısından risk alleli olarak tanımlanmaktadır. Yapılan bir çalışmada, homozigot olanların (AA genotipi) olmayanlara kıyasla vücut ağırlıklarının 3-4 kg daha fazla ve obezite riskinin 1,67 kat daha fazla olduğu bildirilmektedir (16). Yine başka bir çalışmada ise AT ve TT genotipine sahip olan bireylere kıyasla AA genotipine sahip olan bireylerin beden kütle indekslerinin (BKİ) yanı sıra yağ kütlelerinin ve bel çevrelerinin de daha yüksek olduğu belirlenmiştir (26). Yapılan çalışmalarda FTO geninin özellikle beyaz 1rkta obezite gelişimi üzerinde etkili olduğu bildirilmiştir $(28,29)$. Portekizli (beyaz ırk) premenapozal kadın bireyin (95'i obez, 99'u normal ağırlıklı) FTO geni rs9939609 SNP'leri araştırılmış ve FTO rs9939609 risk alleli olan bireylerin 2,5 kat daha fazla obezite riski taşıdığı bulunmuştur (28). Yapılan bazı çalışmalarda da FTO gen polimorfizmleri ile obezite arasında ilişki bulunmamıştır. Bu nedenle, etnik kökenin, FTO gen polimorfizminin obezite gelişimindeki rolü ile ilgili önemli bir değişken olabileceği belirtilmiştir (30,31).

Farklı birçok grupta FTO geni SNP'lerinin obeziteyle ilişkili olduğu belirtilmiş olsa da mekanizmalar hala net değildir (32). FTO geninin enerji metabolizmasında anahtar rol oynayan hipotalamik nükleusta eksprese olmasından dolayı enerji homeostazına katkı sağladığı düşünülmektedir $(33,34)$. FTO geninin beynin hipotalamik bölgesiyle ilişkisi nedeniyle besin alımını kontrol edebileceğiyle ilgili olarak yapılan bir araştırmada FTO rs9939609 risk alleli taşıyıcılarında besin alımının etkilendiği, A alleli ve AA genotipi taşıyıcılarının TT homozigot taşıyıcılara kıyasla diyetle daha fazla enerji aldıkları sonucuna ulaşılmıştır (35). Beslenme durumu ve diyetle alınan enerji miktarının FTO gen polimorfizmi ile ilişkili olduğu bildirilmektedir $(35,36)$. Yapılan bir çalışmada FTO geni rs9939609 varyantı ile diyetle yüksek protein alımı arasında bir ilişki bulunmuştur. Ancak aynı çalışmada sözü edilen FTO gen varyantı ile diyetle alınan toplam enerji ve karbonhidrat miktarı arasındaki ilişkinin göreceli olarak daha zayıf olduğu belirlenmiştir. Çalışmada diyetle alınan toplam enerji ve protein ile FTO geni rs9939609 varyantı arasındaki ilişki istatistiksel olarak BKİ düzeltmesi yapıldıktan sonra da önemliliğini sürdürmüştür (36). Yapılan başka bir çalışmada da FTO fenotipleri ile diyetle alınan toplam enerji miktarı arasında önemli bir ilişki olduğu saptanmış, FTO gen polimorfizminin obezite ile ilişkisinin enerji harcaması üzerinden değil besin alımı üzerinden olduğu bildirilmiştir (35). Bu sonucun desteklendiği birçok çalışmada da FTO allellerinin besin alımını arttırdığı ancak enerji harcaması ile ilişkisinin olmadığı raporlanmıştır (37-41).

Diyetle toplam enerji alımıyla ilgili FTO gen polimorfizmlerinin etki mekanizmalarının açıklanmasında serum leptin ve ghrelin gibi bazı iştah düzenleyici hormonların etkileri öne çıkmaktadır. Bu genin farklı varyasyonlarının (rs9939609, rs17817449 ve rs142085) leptin düzeyini etkilediği ve insülin direncine yol açarak obezite etiyolojisine katkıda bulunduğu bildirilmektedir (42). Yapılan bir çalışmada FTO AA genotipi olan bireylerde TT genotipe sahip bireylere göre açil ghrelin mRNA seviyesinin daha fazla olduğu belirlenmiştir. Ayrıca FTO genindeki aşırı ekspresyonun ghrelin mRNA ve peptid seviyelerini artırdığı saptanmıştır 
(43). Başka bir çalışmada da diyabetik kadınlarda rs9939609 SNP'snin daha düşük adiponektin ve leptin seviyeleri ile ilişkili olduğu gösterilmiştir. Homozigot risk alleli (AA) taşıyan bireylerde insülin cevabının serebrokortikal insülin duyarlılığının etkilenmesi nedeniyle azaldığ 1 belirlenmiştir (44).

Adipoz doku, FTO geninin yüksek seviyede ekspresyon gösterdiği bölgelerden biri olmakla birlikte alınan fazla enerjinin de depolandığı bir bölgedir. Obezitede preadipositlerin farklılaşması ve proliferasyonu önemli bir rol oynamaktadır. Bu nedenle farklı BKİye sahip popülasyonlarda FTO gen ekspresyon seviyelerinin farklı olması da obeziteyle ilişkili bir diğer mekanizma olarak öne sürülmektedir. Yapılan çalışmalarda obez bireylerde adipoz dokuda FTO mRNA seviyelerinin daha yüksek ve FTO mRNA seviyesi ile BKİ arasında pozitif bir ilişki olduğu belirlenmiştir (45-47). Ayrıca FTO geninin iskelet kasında mitokondriyal fonksiyonda rol oynadığı ve bu durumun obeziteyle ilişkili olabileceği de öne sürülmüştür (45). Ayrıca telomer uzunluğunun obezite için bir risk faktörü olduğu ve FTO gen polimorfizmi ile ilişkili olması nedeniyle FTO-obezite mekanizmalarından biri olabileceği düşünülmektedir $(32,48)$.

\section{Melanokortin 4 reseptör geni}

Membrana bağlı bir reseptör tarafından kodlanan melanokortin 4 reseptör geni (MC4R) melanokortin reseptör ailesine aittir. MC4R geni 18q21.32 kromozomu üzerinde bulunmakta ve FTO genine benzer şekilde besin alımının kontrolü ve enerji dengesinde düzenleyici bir rol oynamaktadır $(49,50)$. Bu gende gerçekleşen polimorfizm ve meydana gelen defektler şiddetli obezite gelişimi ile ilişkilidir. MC4R geninin farelerden sonra, obez hastalarda işlevsel olarak ilgili ilk heterozigot mutasyonları bildirilmiştir $(51,52)$. Son yıllarda, obez hastalarda çok sayıda MC4R geni mutasyonu tespit edilmiş ve bu gende şimdiye kadar 200'den fazla mutasyon tespit edilmiştir (53-55). Obez hastaların araştırılan gruplarında MC4R geni mutasyonlarının sıklığı yaklaşık \%5'tir. MC4R geninin esas olarak ATP'yi cAMP'ye dönüştürmek için adenil siklaz aktive eden uyarıcı $\mathrm{G}$ proteininin (Gs) aktivasyonu yoluyla sinyal verdiği bildirilmiştir (56).

En yaygın olarak görülen rs17782313 MC4R gen polimorfizmi, hem Avrupalı yetişkinlerde hem de çocuklarda obez fenotip üzerinde FTO geni ile sinerjistik bir etki göstermektedir $(17,57,58)$. Nadiren, fonksiyon kaybına yol açan MC4R genindeki mutasyonlar, obezitenin monojenik formlarına yol açabilir (17), ancak MC4R geni ile bağlantılı obezite, nadir görülen resesif monojenik obezite formları ile yaygın poligenik formlar arasında duran özel bir form olarak tanımlanır (59). MC4R geninin rs12970134 ve rs17782313 polimorfizmlerinin, hem Asya hem de Avrupa popülasyonlarında çocuk ve yetişkin obezitesi ile ilişkili olduğu belirlenmiştir (17,60-64). Yakın tarihli bir çalışmada, MC4R rs17782313'ün vücut büyüklügü ve yağ dağılımı üzerinde güçlü bir etkisinin olduğu belirtilmiştir. Bu da C / C genotipinin daha yüksek BKİ ile ilişkili olduğunu kanıtlamıştır (65).

Bir diğer önemli keşif, adiponektinin MC4R geninin obezite üzerindeki etkisine aracılık etmede rol oynayabileceğidir (66). Bazı sonuçlara göre, obezite gelişimi için yüksek risk altında olan bireyler hem FTO hem de MC4R genleri için homozigot olabilir veya iki genden biri için homozigot diğeri için heterozigot olabilir (67-69). Yapılan bir çalışmada, rs17782313 MC4R polimorfizminin yeme davranışında ve yeme davranışının kontrolünde anahtar bir rolü olduğu kanıtlanmıştır. Bu nedenle, son zamanlarda obez çocuklar üzerinde yapılan bir çalışma, bu genotipin $\mathrm{C}$ alelini taşıyan obez kızların taşıyıcı olmayanlara kıyasla daha düşük tokluk yanıtı 
verebildiğini ve daha yüksek kontrolsüz yeme skorları gösterdiğini, belirtmiştir. Benzer şekilde hem yetişkinler hem de çocuklar üzerinde yapılan diğer çalışmalar, MC4R ve FTO genlerinin ekspresyonunun yaşam tarzı ve fiziksel aktivite ile düzenlenebileceğini göstermiştir (70,71).

MC4R gen eksikliğinin en belirgin klinik özelliği, şiddetli hiperfajiye bağlı erken başlangıçlı obezitedir $(51,52)$. Homozigot veya bileşik heterozigot varyant taşıyıcılar açlık duyguları açısından daha şiddetli bir klinik fenotip sergilerler (72,73). Ayrıca, bu bireylerde artmış lineer büyüme ve hiperinsülinemi gözlenmiştir $(74,75)$. MC4R gen varyantı taşıyıcıları için tedavi seçenekleri, artan egzersiz ve azaltılmış enerji alımı gibi konservatif yaklaşımları içermektedir. Bunun yanında obez MC4R gen varyantı taşıyıcılarında glukagon benzeri bir peptit 1 reseptörü (GLP-1R) agonisti kullanılarak yapılan farmakolojik tedavi araştırılmaktadır (76). Bununla birlikte, bu GLP-1R agonist tedavisinin potansiyel uzun süreli etkisi hakkında fazla bilgi bulunmamaktadır. Obez MC4R gen varyantı taşıyıcılarında bariatrik cerrahi sonrası vücut ağırlığı artışı görüldüğü bildirilmiştir. İnsanlarda ve hayvan modellerinde yapılan daha önceki çalışmalar, bialelik bir MC4R gen varyantı taşıyıcılarının, bariatrik cerrahi sonrası azaltılmış vücut ağırlığının sürdürülmesine yanıt vermediklerini ve kısa bir vücut ağırlığı kaybından sonra bu bireylerde tekrar ağırlık kazanımı olduğu gösterilmiştir $(77,78)$.

Leptin (tokluk hormonu), ghrelin (açlık hormonu) ve reseptörleri ile uyumlu olarak hareket eden MC4R geni, enerji homeostazı ve vücut ağırlığının düzenlenmesinde önemli bir konuma sahiptir. Paraventriküler çekirdekte (PVN) eksprese edilen MC4R geninin vücut ağırlığı düzenlemesinde önemli bir rol oynadığı ve hipotalamik ağırlık düzenlemesi için çok önemli olan leptin melanokortin yolunun önemli bir bileşeni olduğu ortaya çıkmıştır. MC4R geninin beyinle ilişkili bu mekanizmasının keşfinden sonra obezite tedavisi için potansiyel bir hedef olduğu kabul edilmiştir (79). MC4R geni ve leptin reseptörü, reseptör/ligand sistemlerinden herhangi birindeki genetik kusurlar bozulduğunda, enerji dengesinin bozulmasına neden olan MC4R gen yolunun anahtar bileşenleridir $(80,81)$. Bugüne kadar çeşitli peptit ve küçük moleküllü MC4R gen agonistleri geliştirilmiştir ve kemirgen modellerinde besin alımında ve vücut ağırlığında azalma sağlandığı gösterilmiştir. Bununla birlikte, MC4R gen güdümlü farmakolojik etkililikler, obezite tedavisi için MC4R gen agonisti geliştirmede zorluklar yaratmıştır. Bu engeller arasında kan basıncı ve kalp atım hızının yükselmesine yol açan MC4R geni ile ilişkili sempatik aktivasyon ve cinsel uyarılmanın aktivasyonu yer alır (82$85)$.

\section{FTO ve MC4R genlerinin PKOS ile ilişkisi}

FTO gen varyantlarının yağ kütlesini nasıl etkilediğine dair mekanizma net olarak bilinmemekle birlikte FTO gen varyantlarının yağ kütlesi üzerindeki etkilerden bağımsız olarak PKOS gelişimi üzerine doğrudan etkisinin bulunabildiği gibi bazı hipotezler ileri sürülmektedir.

Ancak, FTO varyantlarının PKOS ile ilgili olarak adipozite gelişimi üzerine direkt etkisinin olmadı̆̆ı bildirilmektedir (86).

Yapılan çalışmalarda FTO geninin PKOS ile önemli derecede ilişkili olduğu ve bu ilişkinin FTO’nun BKİ üzerine olan etkisinden daha önemli olduğu bildirilmiştir $(26,87)$. Derleme bir araştırmanın sonucunda, PKOS'lu hastalarda FTO polimorfizminin BKİ üzerinde etkili olduğu (25), özellikle FTO geni rs9939609 T/A polimorfizmi ve A alleli varlığının PKOS için bir risk faktörü oluşturduğu bulunmuştur (87). Ancak FTO geni rs8050136, rs1121980, rs1558902 ve rs1421085 polimorfizmlerine ilişkin tutarsız sonuçlar bulunmaktadır $(88,89)$. 
Yakın zamanda yapılan bir meta analizde FTO gen polimorfizmi ve PKOS duyarlılığı arasında bir ilişki bulunmamıştır. Ancak alt grup analizlerinde Doğu Asyalılarda anlamlı ilişki bulunurken Beyaz ırkta bir ilişki olmadığ 1 gösterilmiştir. Bu çalışmada özellikle Doğu Asya nüfusunda BKİ ayarlaması yapıldıktan sonra elde edilen anlamlı sonuçlar göz önünde bulundurularak FTO varyantları ile PKOS asarında bir ilişki olabileceği öne sürülmüştür. Çalışma sonunda farklı popülasyonlarda FTO gen analizlerinin araştırılması gerektiği belirtilmiştir (90). Başka bir meta analiz çalışmasında da FTO geni rs9939609 varyantı ile PKOS arasında ilişki bulunurken, rs8050136, rs1421085 varyantları ile ilgili daha fazla çalışma yapılması gerektiği bildirilmiştir (89). Güney Brezilya bölgesinde yapılan bir araştırmada FTO rs9939609 ve rs8050136 polimorfizmlerinin ve haplotiplerinin PKOS ile ilişkili olmadığ bulunmuş, ancak kadınlarda rs9939609 ve rs8050136 risk allellerinin varlı̆̆ı ile glikoz seviyeleri arasında ilişki olduğu bildirilmiştir (91).

Vücut yağ kütlesi ve obezite ile ilişkili FTO genindeki yaygın varyantların BKİ ve yağ kütlesi üzerinde önemli bir etki yoluyla tip 2 DM'da duyarlılığı etkilediği bildirilmektedir (33, 34). FTO geninin doğrudan PKOS ile ilişkisini ortaya koyan bir mekanizma bulunmamaktadır. Ancak, FTO ve PKOS duyarlılı̆̆ PKOS için poligenik bir arka plan oluşturarak adipozitedeki artışın gözlenmesiyle ilişkili olduğunu belirtmektedir (92). FTO'nun tip 2 DM gelişimine karşı yağlanma ve duyarlılık üzerindeki etkisi, obezite ve PKOS arasındaki yakın ilişki ve FTO varyantlarının paylaştığı ortak patofizyolojik ve epidemiyolojik özellikler göz önüne alındığında, FTO varyantlarının bireysel olarak PKOS riskini etkileyebileceği ifade edilmektedir. Böyle bir ilişkinin tespit edilmesi obezitenin ve PKOS'un nedensel olarak ilişkili olduğuna ve gen dizisi varyasyonunun PKOS'a yatkınlığı etkileyebileceğine bir kanıt oluşturmaktadır. Ayrıca yapılacak diğer çalışmaların PKOS ve obeziteyle ilişkili gen ilişkisini açıklamak için daha fazla kanıt oluşturması beklenmektedir. Ayrıca hiperandrojeneminin önemli bir endokrin özellik olduğu ve PKOS tanı kriterlerinin bir parçası olduğu göz önüne alındığında, FTO varyasyonunun PKOS'lu kadınlarda dolaşımdaki testosteron düzeylerini etkileyip etkilemediği de saptanmalıdır $(93,94)$. Yapılan bir çalışmada FTO gen varyantlarının PKOS ve obezite riski ile ilişkili olduğu bildirilmiş, ancak FTO ve androjen seviyeleri arasında bir ilişki bulunmamıştır (86). Başka bir çalışmada da çeşitli genotiplerin taşıyıcıları arasında toplam testosteron düzeyleri ve Free androgen index-serbest androjen indeksi (FAI) değerlerinde hiçbir farklılık görülmemiştir (91). Polonya'da yapılan başka bir çalışmada da testosteron, Seks Hormon Bağlayıcı Globulin (SHBG) ve FAI değerlerinde farklı genotipler arasında fark bulunmamıştır (92). Buna karşın Wehr ve ark. rs9939609 allel varlığında serbest testosteron seviyesinin daha yüksek olduğunu bildirmiştir (95).

Metabolik sendrom belirteçlerinden açlik glikoz seviyelerinde yükselme durumu obez PKOS'lu kadınlarda da sıklıkla görülmektedir. Yapılan bir çalışmada PKOS'lu kadınlarda rs9939609 ve rs8050136 polimorfizmleri risk allellerinin her ikisinin de daha yüksek açlık kan glikozu ile ilişkili olduğu bulunmuştur (91). Benzer şekilde PKOS'lu kadınlarda yapılan başka bir çalışmada da bozulmuş açlık glikozunun BKİ ve yaştan bağımsız olarak Orta Avrupa nüfusunda rs1421085 (C/T) gen polimorfizmi ile ilişkili olduğu bulunmuştur. Bu çalışma aynı zamanda metabolik sendrom ve bileşenleri (özellikle glikoz intoleransı) aracılığıyla PKOS'ta FTO geninin etkili bir rolü olduğuna dair kanıt sunmuş, çalışma sonucunda PKOS'lu kadınlarda obezite veya diğer metabolik komplikasyonların gelişmesine yatkınlık için öngörücü genetik 
belirteçlerin tanımlanmasının gerekli olabileceği belirtilmiştir (96). Geniş bir popülasyonda (17037 beyaz Avrupalı) yapılan bir çalışmada FTO genotipi ile açlık insülin, glikoz, trigliserit ve yüksek yoğunluklu lipoprotein (HDL) kolesterol düzeyleri arasında bir ilişki olduğu bildirilmiştir (97). Ayrıca ilişki bulunmayan çalışmalar bulunmakla birlikte (98-100), FTO genindeki varyantların PKOS'lu kadınlarda hiperandrojenemi, ağırlık, boy uzunluğu, bel ve kalça çevresi gibi parametreleri etkilediği de gösterilmiştir (95). Menapoz öncesi kadınlarda yapılan bir çalışmada da FTO genotipleri ve yüksek glikoz seviyeleri arasındaki ilişki belirtilmiştir (101).

Obezite ile kombinasyon halinde PKOS'a yatkınlıkta FTO geninin değişken rolü nedeniyle, bu fenotiplerle ilişkili FTO'nun farklı etnik yapıdaki kesin katkısını araştırmak önemlidir. Pakistan nüfusunda FTO geninin rolünü araştırmak amacıyla incelenen SNP rs9939609 Pakistanlı kadınlarda BKİ ve obezite riski ile bağlantılı bulunmuştur. FTO geni rs9939609 varyantının metabolik biyokimyasal parametrelerle ilişkisi, bu polimorfizmin kadınlarda metabolizmayı bozabileceğini ve bunları obezite ve tip-2 diyabete yatkın hale getirebileceğini göstermektedir (102). Çin'de yapılan bir çalışmada hem obez hem de obez olmayan PKOS'lu grupta FTO geni rs9939609 varyantı ile PKOS arasında anlamlı ilişki bulunmuştur. FTO geninin obeziteyle PKOS'u birbirine bağlayan moleküler belirleyicilerden biri olması gerektiği varsayılmaktadır. FTO geni, hiperandrojenizmi modüle etmede önemli olan ve PKOS'un yumurtalık disfonksiyonunda rol oynayan epigenetik düzenleyici süreçlerde ve nükleik asit onarım veya modifikasyon süreçlerinde transkripsiyonel bir koaktivatör görevi görür. Genel mekanizma ve epigenetik düzenlemede FTO geninin rolü, FTO geninin PKOS, obezite ve Tip 2 DM gibi çeşitli hastalıklarda yer alan bir pleiotropik faktör olabileceğini düşündürmektedir. Bununla birlikte, PKOS'ta FTO gen proteininin işlevi ve biyolojik yolları tam olarak dikkate alınmamıştır (103). Polikistik over sendrom hastalarında obezite gelişimi üzerine FTO geninin etkisinin hangi mekanizmalarla gerçekleştiğinin anlaşılabilmesi için daha ileri çalışmaların yapılmasına ihtiyaç vardır.

FTO geni PKOS ile oldukça ilişkili bulunmakla birlikte MC4R gen polimorfizmi ile orta düzeyde bir ilişkiye sahip olduğu ifade edilmiştir. Bununla birlikte, besin alımı ve enerji tüketiminin kontrolündeki benzer işlevlerine dayanarak FTO ve MC4R genlerinin kombine halde PKOS'un duyarlılığına katkıda bulunabileceği ifade edilmiş, hem FTO hem de MC4R genlerinin risk alelleri pozitif olan hastalarda PKOS görülme olasılığının FTO veya MC4R risk alelleri ayrı ayrı pozitif olan hastalardan daha yüksek olduğu bildirilmiştir. FTO ve PKOS rs9939609 arasında anlamlı bir ilişki gözlenmiştir, ancak ilişki BKİ için düzenleme yapıldıktan sonra zayıflamıştır. Bununla birlikte, MC4R rs17782313, PKOS için artmış bir riskle ilişkili bulunmamış ve FTO ve MC4R gen polimorfizmlerinin etkileşiminin PKOS'un gelişiminde, daha anlamlı bir ilişki sergilediği bulunmuştur (104). Suudi Arabistan'daki PKOS hastalarında hem SNP'ler (rs12970134 ve rs17782313) hem de yüksek BKİ arasında oldukça anlamlı bir ilişki tespit edilmiştir. Bununla birlikte, MC4R SNP'ler ile PKOS arasında doğrudan bir ilişki bulunmamıştır (105). Ancak bu alellerin, obezitedeki MC4R gen varyantları için küresel risk allelleri olduğu öngörülmüştür $(60,106)$. Başka bir çalışmada da MC4R SNP'ler (rs12970134 ve rs17782313) ile obezite arasında bir ilişki olduğu, ancak SNP'lerin PKOS için risk faktörü olmadığ anlaşılmıştır (107,108). Literatürde PKOS'lularda MC4R SNP'ler (rs12970134 ve rs17782313) ve BKİ arasında ilişki bulunmayan çalışmalar da bulunmaktadır (109). Obez olmayan hastalar arasinda sirasiyla rs 12970134 ve rs17782313'teki homozigot veya heterozigot 
durumlarda $\mathrm{G}$ ve T alelleri, hirsutizm, saç dökülmesi ve yüksek AMH dahil PKOS semptomları ile ilişkilidir. Bu nedenle, yüksek BKİ (>30 kg/m2), Suudi Arabistan'daki PKOS'un ana nedeni olarak bildirilmiştir. Ayrıca zayıf PKOS grubunda zayıf prognozun, ters genotiplerle ilişkili olabileceği de bildirilmiştir (105). Daha önce Mahmoudi ve ark. altı MC4R gen varyantı ile kadın tipi saç dökülmesi arasındaki ilişkiyi incelemiş ancak PKOS dışı kişilerde; genotipli varyantların hiçbirinde anlamlı bir ilişki görülmemiştir (110).

\section{SONUÇ}

Polikistik over sendromunun obeziteyle olan ilişkisi düşünüldüğünde, bu karmaşık fenotipin altında yatan genlerin de etkileşimini dikkate almak gerekmektedir. Obeziteyle ilişkili gen polimorfizmlerinin PKOS'u dolaylı yoldan etkileyebileceğine dair çalışmalar görülmekle birlikte, herhangi bir ilişki bulunmayan çalışmalar da bulunmaktadır. Temelde obezitenin mi PKOS'a PKOS'un mu obeziteye neden olduğuna ilişkin net bir bilgi bulunamamaktadır. Obeziteyle ilişkili genlerle PKOS arasındaki ilişkinin incelendiği çalışmalar da çoğunlukla FTO ve MC4R genlerinin belli varyantları üzerinde durulmaktadır. Ancak obeziteyle ilişkili olan bu genlerin farklı varyantları veya farklı gen polimorfizmlerinin etkilerinin belirlenebilmesi için daha fazla sayıda çalışma yapılmasına ihtiyaç vardır.

Sonuç olarak, yapılan çalışmalarda çoğunlukla FTO ve MC4R genlerindeki SNP'lerin PKOS'lu kadınlarda BKİ ile ilişkili olduğu, ancak PKOS'un üreme fenotiplerine önemli bir şekilde katkıda bulunmadığı görülmüştür. Bununla birlikte, bu varyantlar, PKOS'un bir oligojenik / polijenik bozukluk olduğu fikrine uygun olarak kadınların PKOS'a yatkınlıklarını artırmada bu genlerin birbirleri veya başka genlerle de etkileşime girebileceği göz önünde bulundurulmalıdır.

\section{KAYNAKLAR}

1. Sirmans, S. M., \& Pate, K. A. (2014). Epidemiology, diagnosis, and management of polycystic ovary syndrome. Clinical Epidemiology, 6, 1-13.

2. Azziz, R., \& Kashar-Miller, M. (2000). Family history as a risk factor for the polycystic ovary syndrome. Journal of Pediatric Endocrinology \& Metabolism: JPEM, 13, 1303 1306.

3. Kahsar-Miller, M. D., Nixon, C., Boots, L. R., Go, R. C., \& Azziz, R. (2001). Prevalence of polycystic ovary syndrome (PCOS) in first-degree relatives of patients with PCOS. Fertility and Sterility, 75(1), 53-58.

4. Urbanek, M., \& Spielman, R. S. (2002). Genetic analysis of candidate genes for the polycystic ovary syndrome. Current Opinion in Endocrinology, Diabetes and Obesity, 9(6), 492-501.

5. Wood, J. R., Nelson, V. L., Ho, C., Jansen, E., Wang, C. Y., Urbanek, M., et al. (2003). The molecular phenotype of polycystic ovary syndrome (PCOS) theca cells and new candidate PCOS genes defined by microarray analysis. Journal of Biological Chemistry, 278(29), 26380-26390.

6. Battaglia, C., Mancini, F., Cianciosi, A., Busacchi, P., Persico, N., Paradisi, R., et al. (2009). Cardiovascular risk in normal weight, eumenorrheic, nonhirsute daughters of patients with polycystic ovary syndrome: a pilot study. Fertility and Sterility, 92(1), 240-249. 
7. Cheang, K., Nestler, J., \& Futterweit, W. (2008). Risk of cardiovascular events in mothers of women with polycystic ovary syndrome. Endocrine Practice, 14(9), 10841094.

8. Yildiz, B. O., Yarali, H., Oguz, H., \& Bayraktar, M. (2003). Glucose intolerance, insulin resistance, and hyperandrogenemia in first degree relatives of women with polycystic ovary syndrome. The Journal of Clinical Endocrinology \& Metabolism, 88(5), 20312036.

9. Coviello, A. D., Sam, S., Legro, R. S., \& Dunaif, A. (2009). High prevalence of metabolic syndrome in first-degree male relatives of women with polycystic ovary syndrome is related to high rates of obesity. The Journal of Clinical Endocrinology \& Metabolism, 94(11), 4361-4366.

10. Sam, S., Coviello, A. D., Sung, Y. A., Legro, R. S., \& Dunaif, A. (2008). Metabolic phenotype in the brothers of women with polycystic ovary syndrome. Diabetes Care, 31(6), 1237-1241.

11. Covrig, M. (2008). Polycystic ovary syndrome: Diet, micronutrient status and eating behaviour (Doctoral dissertation, University of Oslo).

12. Bozkaya, Ö. G. (2009). Klinisyenler için mutasyon ve polimorfizm. Turkiye Klinikleri Journal of Pediatrics, 18(2), 47-53.

13. Miller, R. D., \& Kwok, P. Y. (2001). The birth and death of human single-nucleotide polymorphisms: new experimental evidence and implications for human history and medicine. Human Molecular Genetics, 10(20), 2195-2198.

14. Lonetti, A., Fontana, M. C., Martinelli, G., \& Iacobucci, I. (2016). Single nucleotide polymorphisms as genomic markers for high-throughput pharmacogenomic studies. In Microarray Technology (pp. 143-159). Humana Press, New York, NY.

15. Thorisson, G. A., Smith, A. V., Krishnan, L., \& Stein, L. D. (2005). The international HapMap project web site. Genome Research, 15(11), 1592-1593.

16. Loos, R., \& Bouchard, C. (2008). FTO: the first gene contributing to common forms of human obesity. Obesity Reviews, 9(3), 246-250.

17. Loos, R. J., Lindgren, C. M., Li, S., Wheeler, E., Zhao, J. H., Prokopenko, I., et al. (2008). Common variants near MC4R are associated with fat mass, weight and risk of obesity. Nature Genetics, 40(6), 768-775.

18. İnternet. U.S. National Library of Medicine. FTO gene. URL: https://ghr.nlm.nih.gov/gene/FTO\#location (Son Erişim Tarihi:01.11.2019.)

19. Mărginean, C. O., Mărginean, C., \& Meliţ, L. E. (2018). New insights regarding genetic aspects of childhood obesity: a minireview. Frontiers in Pediatrics, 6, 271.

20. Apalasamy, Y., Ming, M., Rampal, S., Bulgiba, A., \& Mohamed, Z. (2012). Genetic association of SNPs in the FTO gene and predisposition to obesity in Malaysian Malays. Brazilian Journal of Medical and Biological Research, 45(12), 1119-1126.

21. Gerken, T., Girard, C. A., Tung, Y.-C. L., Webby, C. J., Saudek, V., Hewitson, K. S., et al. (2007). The obesity-associated FTO gene encodes a 2-oxoglutarate-dependent nucleic acid demethylase. Science, 318(5855), 1469-1472.

22. Fawcett, K. A., \& Barroso, I. (2010). The genetics of obesity: FTO leads the way. Trends in Genetics, 26(6), 266-274.

23. Larder, R., Cheung, M. M., Tung, Y. L., Yeo, G. S., \& Coll, A. P. (2011). Where to go with FTO? Trends in Endocrinology \& Metabolism, 22(2), 53-59.

24. Sanchez-Pulido, L., \& Andrade-Navarro, M. A. (2007). The FTO (fat mass and obesity associated) gene codes for a novel member of the non-heme dioxygenase superfamily. BMC Biochemistry, 8(1), 23. 
25. Wojciechowski, P., et al. (2012). Impact of FTO genotypes on BMI and weight in polycystic ovary syndrome: a systematic review and meta-analysis. Diabetologia, 55(10), 2636-2645.

26. Zhao, X., Yang, Y., Sun, B.-F., Zhao, Y.-L., \& Yang, Y.-G. (2014). FTO and obesity: mechanisms of association. Current Diabetes Reports, 14(5), 486.

27. Gu, H. F., Alvarsson, A., \& Brismar, K. (2010). The common FTO genetic polymorphism rs 9939609 is associated with increased BMI in type 1 diabetes but not with diabetic nephropathy. Biomarker Insights, 5, 29-32.

28. Carlos, F. F., Silva-Nunes, J., Flores, O., Brito, M., Doria, G., Veiga, L., et al. (2013). Association of FTO and PPARG polymorphisms with obesity in Portuguese women. Diabetes, Metabolic Syndrome and Obesity: Targets and Therapy, 6, 241.

29. Quan, L., Wang, H., Tian, Y., Mu, X., Zhang, Y., \& Tao, K. (2015). Association of fatmass and obesity-associated gene FTO rs9939609 polymorphism with the risk of obesity among children and adolescents: a meta-analysis. Eur Rev Med Pharmacol Sci, 19(4), 614-623.

30. de Araújo Pereira, P., Alvim-Soares Jr, A. M., Sandrim, V. C., Lanna, C. M. M., SouzaCosta, D. C., de Almeida Belo, V., et al. (2016). Lack of association between genetic polymorphism of FTO, AKT1 and AKTIP in childhood overweight and obesity. Jornal de Pediatria (Versão em Português), 92(5), 521-527.

31. Grant, S. F., Li, M., Bradfield, J. P., Kim, C. E., Annaiah, K., Santa, E., et al. (2008). Association analysis of the FTO gene with obesity in children of Caucasian and African ancestry reveals a common tagging SNP. PLoS One, 3(3), e1746.

32. Zhou, Y., Simmons, D., Lai, D., Hambly, B. D., \& McLachlan, C. S. (2017). rs9939609 FTO genotype associations with FTO methylation level influences body mass and telomere length in an Australian rural population. International Journal of Obesity, 41(9), 1427-1433.

33. Dina, C., Meyre, D., Gallina, S., Durand, E., Körner, A., Jacobson, P., et al. (2007). Variation in FTO contributes to childhood obesity and severe adult obesity. Nature Genetics, 39(6), 724-726.

34. Frayling, T. M., Timpson, N. J., Weedon, M. N., Zeggini, E., Freathy, R. M., Lindgren, C. M., et al. (2007). A common variant in the FTO gene is associated with body mass index and predisposes to childhood and adult obesity. Science, 316(5826), 889-894.

35. Speakman, J. R., Rance, K. A., \& Johnstone, A. M. (2008). Polymorphisms of the FTO gene are associated with variation in energy intake, but not energy expenditure. Obesity, 16(8), 1961-1965.

36. Qi, Q., Kilpeläinen, T. O., Downer, M. K., Tanaka, T., Smith, C. E., Sluijs, I., et al. (2014). FTO genetic variants, dietary intake and body mass index: insights from 177 330 individuals. Human Molecular Genetics, 23(25), 6961-6972.

37. Cecil, J. E., Tavendale, R., Watt, P., Hetherington, M. M., \& Palmer, C. N. (2008). An obesity-associated FTO gene variant and increased energy intake in children. New England Journal of Medicine, 359(24), 2558-2566.

38. McCaffery, J. M., Papandonatos, G. D., Peter, I., Huggins, G. S., Raynor, H. A., Delahanty, L. M., et al. (2012). Obesity susceptibility loci and dietary intake in the Look AHEAD Trial. The American Journal of Clinical Nutrition, 95(6), 1477-1486.

39. Müller, T. D., Tschöp, M. H., \& Hofmann, S. (2013). Emerging function of fat mass and obesity-associated protein (fto). PLoS Genetics, 9(1), e1003223.

40. Speakman, J. R. (2010). FTO effect on energy demand versus food intake. Nature, 464(7289), E1.

41. Wardle, J., Llewellyn, C., Sanderson, S., \& Plomin, R. (2009). The FTO gene and measured food intake in children. International Journal of Obesity, 33(1), 42-45. 
42. Do, R., Bailey, S. D., Desbiens, K., Belisle, A., Montpetit, A., Bouchard, C., et al. (2008). Genetic variants of FTO influence adiposity, insulin sensitivity, leptin levels, and resting metabolic rate in the Quebec Family Study. Diabetes, 57(4), 1147-1150.

43. Karra, E., O’Daly, O. G., Choudhury, A. I., Yousseif, A., Millership, S., Neary, M. T., et al. (2013). A link between FTO, ghrelin, and impaired brain food-cue responsivity. The Journal of Clinical Investigation, 123(8), 3539-3551.

44. Tschritter, O., Preissl, H., Yokoyama, Y., Machicao, F., Häring, H.-U., \& Fritsche, A. (2007). Variation in the FTO gene locus is associated with cerebrocortical insulin resistance in humans. Diabetologia, 50(12), 2602-2603.

45. Grunnet, L. G., Nilsson, E., Ling, C., Hansen, T., Pedersen, O., Groop, L., et al. (2009). Regulation and function of FTO mRNA expression in human skeletal muscle and subcutaneous adipose tissue. Diabetes, 58(10), 2402-2408.

46. Lappalainen, T., Kolehmainen, M., Schwab, U., Pulkkinen, L., de Mello, V. D., Vaittinen, M., et al. (2010). Gene expression of FTO in human subcutaneous adipose tissue, peripheral blood mononuclear cells and adipocyte cell line. Lifestyle Genomics, 3(1), 37-45.

47. Tews, D., Fischer-Posovszky, P., \& Wabitsch, M. (2011). Regulation of FTO and FTM expression during human preadipocyte differentiation. Hormone and Metabolic Research, 43(01), 17-21.

48. Dlouha, D., Pitha, J., Lanska, V., \& Hubacek, J. (2012). Association between FTO 1st intron tagging variant and telomere length in middle aged females. 3PMFs study. Clinica Chimica Acta, 413(15-16), 1222-1225.

49. Razquin, C., Marti, A., \& Martinez, J. A. (2011). Evidences on three relevant obesogenes: MC4R, FTO and PPAR $\gamma$. Approaches for personalized nutrition. Molecular Nutrition \& Food Research, 55(1), 136-149.

50. Willer, C. J., Speliotes, E. K., Loos, R. J., Li, S., Lindgren, C. M., Heid, I. M., et al. (2009). Six new loci associated with body mass index highlight a neuronal influence on body weight regulation. Nature Genetics, 41(1), 25-34.

51. Vaisse, C., Clement, K., Guy-Grand, B., \& Froguel, P. (1998). A frameshift mutation in human MC4R is associated with a dominant form of obesity. Nature Genetics, 20(2), 113-114.

52. Yeo, G. S., Farooqi, I. S., Aminian, S., Halsall, D. J., Stanhope, R. G., \& O'Rahilly, S. (1998). A frameshift mutation in MC4R associated with dominantly inherited human obesity. Nature Genetics, 20(2), 111-112.

53. Collet, T.-H., Dubern, B., Mokrosinski, J., Connors, H., Keogh, J. M., de Oliveira, E. M., et al. (2017). Evaluation of a melanocortin-4 receptor (MC4R) agonist (Setmelanotide) in MC4R deficiency. Molecular Metabolism, 6(10), 1321-1329.

54. Hinney, A., Bettecken, T., Tarnow, P., Brumm, H., Reichwald, K., Lichtner, P., et al. (2006). Prevalence, spectrum, and functional characterization of melanocortin-4 receptor gene mutations in a representative population-based sample and obese adults from Germany. The Journal of Clinical Endocrinology \& Metabolism, 91(5), 17611769.

55. Tao, Y. X. (2009). Mutations in melanocortin-4 receptor and human obesity. Progress in Molecular Biology and Translational Science, 88, 173-204.

56. Stutzmann, F., Tan, K., Vatin, V., Dina, C., Jouret, B., Tichet, J., et al. (2008). Prevalence of melanocortin-4 receptor deficiency in Europeans and their age-dependent penetrance in multigenerational pedigrees. Diabetes, 57(9), 2511-2518.

57. Lazopoulou, N., Gioka, E., Ntalla, I., Pervanidou, P., Magiakou, A.-M., RomaGiannikou, E., et al. (2015). The combined effect of MC4R and FTO risk alleles on childhood obesity in Greece. Hormones, 14(1), 126-133. 
58. Xi, B., Chandak, G. R., Shen, Y., Wang, Q., \& Zhou, D. (2012). Association between common polymorphism near the MC4R gene and obesity risk: a systematic review and meta-analysis. PLoS One, 7(9), e45731.

59. Tounian, P. (2011). Programming towards childhood obesity. Annals of Nutrition and Metabolism, 58(Suppl. 2), 30-41.

60. Chambers, J. C., Elliott, P., Zabaneh, D., Zhang, W., Li, Y., Froguel, P., et al. (2008). Common genetic variation near MC4R is associated with waist circumference and insulin resistance. Nature Genetics, 40(6), 716-718.

61. Dwivedi, O. P., Tabassum, R., Chauhan, G., Kaur, I., Ghosh, S., Marwaha, R. K., et al. (2013). Strong influence of variants near MC4R on adiposity in children and adults: a cross-sectional study in Indian population. Journal of Human Genetics, 58(1), 27-32.

62. Scherag, A., Jarick, I., Grothe, J., Biebermann, H., Scherag, S., Volckmar, A.-L., et al. (2010). Investigation of a genome wide association signal for obesity: synthetic association and haplotype analyses at the melanocortin 4 receptor gene locus. PLoS One, 5(11), e13967.

63. Vogel, C. I., Boes, T., Reinehr, T., Roth, C. L., Scherag, S., Scherag, A., et al. (2011). Common variants near MC4R: exploring gender effects in overweight and obese children and adolescents participating in a lifestyle intervention. Obesity Facts, 4(1), 67-75.

64. Zhao, J., Bradfield, J. P., Li, M., Wang, K., Zhang, H., Kim, C. E., et al. (2009). The role of obesity-associated loci identified in genome-wide association studies in the determination of pediatric BMI. Obesity, 17(12), 2254-2257.

65. Bordoni, L., Marchegiani, F., Piangerelli, M., Napolioni, V., \& Gabbianelli, R. (2017). Obesity-related genetic polymorphisms and adiposity indices in a young Italian population. IUBMB Life, 69(2), 98-105.

66. Wu, L., Gao, L., Zhao, X., Zhang, M., Wu, J., \& Mi, J. (2017). Associations of two obesity-related single-nucleotide polymorphisms with adiponectin in Chinese children. International Journal of Endocrinology. https://doi.org/10.1155/2017/6437542

67. Day, F. R., \& Loos, R. J. (2011). Developments in obesity genetics in the era of genomewide association studies. Lifestyle Genomics, 4(4), 222-238.

68. Farajian, P., Panagiotakos, D. B., Risvas, G., Karasouli, K., Bountziouka, V., Voutzourakis, N., et al. (2013). Socio-economic and demographic determinants of childhood obesity prevalence in Greece: the GRECO (Greek Childhood Obesity) study. Public Health Nutrition, 16(2), 240-247.

69. Walters, R. G., Jacquemont, S., Valsesia, A., De Smith, A., Martinet, D., Andersson, J., et al. (2010). A new highly penetrant form of obesity due to deletions on chromosome 16p11. 2. Nature, 463(7281), 671-675.

70. Ortega-Azorín, C., Sorlí, J. V., Asensio, E. M., Coltell, O., Martínez-González, M. Á., Salas-Salvadó, J., et al. (2012). Associations of the FTO rs9939609 and the MC4R rs 17782313 polymorphisms with type 2 diabetes are modulated by diet, being higher when adherence to the Mediterranean diet pattern is low. Cardiovascular Diabetology, 11(1), 137.

71. Xi, B., Wang, C., Wu, L., Zhang, M., Shen, Y., Zhao, X., et al. (2011). Influence of physical inactivity on associations between single nucleotide polymorphisms and genetic predisposition to childhood obesity. American Journal of Epidemiology, 173(11), 1256-1262.

72. Hainerová, I., Larsen, L. H., Holst, B., Finková, M., Hainer, V., Lebl, J., et al. (2007). Melanocortin 4 receptor mutations in obese Czech children: studies of prevalence, phenotype development, weight reduction response, and functional analysis. The Journal of Clinical Endocrinology \& Metabolism, 92(9), 3689-3696. 
73. Hinney, A., Bettecken, T., Tarnow, P., Brumm, H., Reichwald, K., Lichtner, P., et al. (2006). Prevalence, spectrum, and functional characterization of melanocortin-4 receptor gene mutations in a representative population-based sample and obese adults from Germany. The Journal of Clinical Endocrinology \& Metabolism, 91(5), 17611769.

74. Dubern, B., Bisbis, S., Talbaoui, H., Le Beyec, J., Tounian, P., Lacorte, J.-M., et al. (2007). Homozygous null mutation of the melanocortin-4 receptor and severe earlyonset obesity. The Journal of Pediatrics, 150(6), 613-617. e611.

75. Farooqi, I. S., Keogh, J. M., Yeo, G. S., Lank, E. J., Cheetham, T., \& O'Rahilly, S. (2003). Clinical spectrum of obesity and mutations in the melanocortin 4 receptor gene. New England Journal of Medicine, 348(12), 1085-1095.

76. Iepsen, E. W., Zhang, J., Thomsen, H. S., Hansen, E. L., Hollensted, M., Madsbad, S., et al. (2018). Patients with obesity caused by melanocortin-4 receptor mutations can be treated with a glucagon-like peptide-1 receptor agonist. Cell Metabolism, 28(1), 23-32. e23.

77. Aslan, I., Ranadive, S. A., Ersoy, B. A., Rogers, S. J., Lustig, R. H., \& Vaisse, C. (2011). Bariatric surgery in a patient with complete MC4R deficiency. International Journal of Obesity, 35(3), 457.

78. Hatoum, I. J., Stylopoulos, N., Vanhoose, A. M., Boyd, K. L., Yin, D. P., Ellacott, K. L., et al. (2012). Melanocortin-4 receptor signaling is required for weight loss after gastric bypass surgery. The Journal of Clinical Endocrinology \& Metabolism, 97(6), E1023-E1031.

79. Kühnen, P., Krude, H., \& Biebermann, H. (2019). Melanocortin-4 receptor signalling: importance for weight regulation and obesity treatment. Trends in Molecular Medicine, 25(2), 136-148.

80. Balthasar, N., Coppari, R., McMinn, J., Liu, S. M., Lee, C. E., Tang, V., et al. (2004). Leptin receptor signaling in POMC neurons is required for normal body weight homeostasis. Neuron, 42(6), 983-991.

81. Lee, Y. S. (2009). The role of leptin-melanocortin system and human weight regulation: lessons from experiments of nature. Annals Academy of Medicine Singapore, 38(1), 34.

82. Greenfield, J. R., Miller, J. W., Keogh, J. M., Henning, E., Satterwhite, J. H., Cameron, G. S., et al. (2009). Modulation of blood pressure by central melanocortinergic pathways. New England Journal of Medicine, 360(1), 44-52.

83. Kuo, J. J., da Silva, A. A., Tallam, L. S., \& Hall, J. E. (2004). Role of adrenergic activity in pressor responses to chronic melanocortin receptor activation. Hypertension, 43(2), 370-375.

84. Martin, W. J., \& MacIntyre, D. E. (2004). Melanocortin receptors and erectile function. European Urology, 45(6), 706-713.

85. Van der Ploeg, L. H., Martin, W. J., Howard, A. D., Nargund, R. P., Austin, C. P., Guan, X., et al. (2002). A role for the melanocortin 4 receptor in sexual function. Proceedings of the National Academy of Sciences, 99(17), 11381-11386.

86. Barber, T., Bennett, A., Groves, C., Sovio, U., Ruokonen, A., Martikainen, H., et al. (2008). Association of variants in the fat mass and obesity associated (FTO) gene with polycystic ovary syndrome. Diabetologia, 51(7), 1153-1158.

87. Liu, A. L., Xie, H. J., Xie, H. Y., Liu, J., Yin, J., Hu, J. S., et al. (2017). Association between fat mass and obesity associated (FTO) gene rs9939609 A/T polymorphism and polycystic ovary syndrome: a systematic review and meta-analysis. BMC Medical Genetics, 18(1), 89. https://doi.org/10.1186/s12881-017-0452-1. 
88. Xue, H., Zhao, H., Zhao, Y., Liu, X., Chen, Z., \& Ma, J. (2015). Association of common variants of FTO in women with polycystic ovary syndrome. International Journal of Clinical and Experimental Pathology, 8(10), 13505-13509.

89. Ying, L., \& Yongxia, C. (2017). Fat mass and obesity associated gene polymorphism and the risk of polycystic ovary syndrome: a meta-analysis. Iranian Journal of Public Health, 46(1), 4-11.

90. Cai, X., Liu, C., \& Mou, S. (2014). Association between fat mass-and obesity-associated (FTO) gene polymorphism and polycystic ovary syndrome: a meta-analysis. PLoS One, 9(1), e86972.

91. Ramos, R. B., \& Spritzer, P. M. (2015). FTO gene variants are not associated with polycystic ovary syndrome in women from Southern Brazil. Gene, 560(1), 25-29.

92. Kowalska, I., Malecki, M., Straczkowski, M., Skupien, J., Karczewska-Kupczewska, M., Nikolajuk, A., et al. (2009). The FTO gene modifies weight, fat mass and insulin sensitivity in women with polycystic ovary syndrome, where its role may be larger than in other phenotypes. Diabetes \& Metabolism, 35(4), 328-331.

93. Barber, T., McCarthy, M., Wass, J., \& Franks, S. (2006). Obesity and polycystic ovary syndrome. Clinical Endocrinology, 65(2), 137-145.

94. Rotterdam, E., \& Group, A.-S. P. C. W. (2004). Revised 2003 consensus on diagnostic criteria and long-term health risks related to polycystic ovary syndrome. Fertility and Sterility, 81(1), 19.

95. Wehr, E., Schweighofer, N., Möller, R., Giuliani, A., Pieber, T. R., \& ObermayerPietsch, B. (2010). Association of FTO gene with hyperandrogenemia and metabolic parameters in women with polycystic ovary syndrome. Metabolism, 59(4), 575-580.

96. Attaoua, R., El Mkadem, S. A., Radian, S., Fica, S., Hanzu, F., Albu, A., et al. (2008). FTO gene associates to metabolic syndrome in women with polycystic ovary syndrome. Biochemical and Biophysical Research Communications, 373(2), 230-234.

97. Freathy, R. M., Timpson, N. J., Lawlor, D. A., Pouta, A., Ben-Shlomo, Y., Ruokonen, A., et al. (2008). Common variation in the FTO gene alters diabetes-related metabolic traits to the extent expected given its effect on BMI. Diabetes, 57(5), 1419-1426.

98. Kowalska, I., Adamska, A., T. Malecki, M., Karczewska-Kupczewska, M., Nikolajuk, A., Szopa, M., et al. (2012). Impact of the FTO gene variation on fat oxidation and its potential influence on body weight in women with polycystic ovary syndrome. Clinical Endocrinology, 77(1), 120-125.

99. Kim, J. J., Choi, Y. M., Hong, M. A., Kim, J. M., Hwang, S. S., Lee, G. H., et al. (2014). Gene dose effect between a fat mass and obesity-associated polymorphism and body mass index was observed in Korean women with polycystic ovary syndrome but not in control women. Fertility and Sterility, 102(4), 1143-1148.

100. Song, D. K., Lee, H., Oh, J.-Y., Hong, Y. S., \& Sung, Y.-A. (2014). FTO gene variants are associated with PCOS susceptibility and hyperandrogenemia in young Korean women. Diabetes \& Metabolism Journal, 38(4), 302-310.

101. Ramos, R. B., Casanova, G. K., Maturana, M. A., \& Spritzer, P. M. (2011). Variations in the fat mass and obesity-associated (FTO) gene are related to glucose levels and higher lipid accumulation product in postmenopausal women from southern Brazil. Fertility and Sterility, 96(4), 974-979.

102. Shahid, A., Rana, S., Saeed, S., Imran, M., Afzal, N., \& Mahmood, S. (2013). Common variant of FTO gene, rs9939609, and obesity in Pakistani females. BioMed Research International. https://doi.org/10.1155/2013/324093.

103. Li, T., Wu, K., You, L., Xing, X., Wang, P., Cui, L., et al. (2013). Common variant rs9939609 in gene FTO confers risk to polycystic ovary syndrome. PLoS One, 8(7), e66250. 
104. Yuan, H., Zhu, G., Wang, F., Wang, X., Guo, H., \& Shen, M. (2015). Interaction between common variants of FTO and MC4R is associated with risk of PCOS. Reproductive Biology and Endocrinology, 13(1), 55.

105. Batarfi, A. A., Filimban, N., Bajouh, O. S., Dallol, A., Chaudhary, A. G., \& Bakhashab, S. (2019). MC4R variants rs12970134 and rs17782313 are associated with obese polycystic ovary syndrome patients in the Western region of Saudi Arabia. BMC Medical Genetics, 20(1), 144.

106. Thorleifsson, G., Walters, G. B., Gudbjartsson, D. F., Steinthorsdottir, V., Sulem, P., Helgadottir, A., et al. (2009). Genome-wide association yields new sequence variants at seven loci that associate with measures of obesity. Nature Genetics, 41(1), 18-24.

107. Ewens, K. G., Jones, M. R., Ankener, W., Stewart, D. R., Urbanek, M., Dunaif, A., et al. (2011). FTO and MC4R gene variants are associated with obesity in polycystic ovary syndrome. PLoS One, 6(1), e16390.

108. Louwers, Y. V., Rayner, N. W., Herrera, B. M., Stolk, L., Groves, C. J., Barber, T. M., et al. (2014). BMI-associated alleles do not constitute risk alleles for polycystic ovary syndrome independently of BMI: a case-control study. PLoS One, 9(1), e87335.

109. Tan, S., Scherag, A., Janssen, O. E., Hahn, S., Lahner, H., Dietz, T., et al. (2010). Large effects on body mass index and insulin resistance of fat mass and obesity associated gene (FTO) variants in patients with polycystic ovary syndrome (PCOS). BMC Medical Genetics, 11(1), 12.

110. Mahmoudi, H., Redler, S., Birch, P., Drichel, D., Dobson, K., Tazi-Ahnini, R., et al. (2013). Selected variants of the melanocortin 4 receptor gene (MC4R) do not confer susceptibility to female pattern hair loss. Archives of Dermatological Research, 305(3), 249-253.

1. 